\title{
Pharmaceutical promotional literature: opinions of physicians in a tertiary care hospital in Mumbai
}

\author{
Kunal Chitnis ${ }^{1}$, Amod Limaye ${ }^{1}$, Manisha Bhosale ${ }^{2 *}$
}

\begin{abstract}
${ }^{1}$ Department of Pharmacology, T.N. Medical College and Nair Hospital, Mumbai, India

${ }^{2}$ Department of Pharmacology, B.J. Medical College and Sasson General Hospital, Pune, India
\end{abstract}

Received: 21 June 2013

Accepted: 21 July 2013

\author{
*Correspondence to: \\ Dr. Manisha Bhosale, \\ Email: \\ drmanisha17sp@gmail.com
}

(C) 2013 Chitnis $\mathrm{K}$ et al. This is an open-access article distributed under the terms of the Creative Commons Attribution NonCommercial License, which permits unrestricted noncommercial use, distribution, and reproduction in any medium, provided the original work is properly cited.

\begin{abstract}
Backgrounds: The aim of this study was to assess physician's opinion regarding pharmaceutical promotional material and make an objective assessment about their opinion on current drug promotional methods.

Methods: 250 questionnaires were sent to physicians. Questionnaires was based on question assessing physicians opinion about 1) Influence of information provided on their prescription writing pattern. 2) Most common information which they seek for and find missing, was assessed on a Likert scale of 1 to 5 for each type of information 3) Type of promotional material preferred for drug information. 4) Significance of the various types of references cited which was assessed on likert scale of 1 to 5 .

Results: 207 questionnaires were returned. $59.5 \%$ of the physicians were of the opinion that the information provide in promotional literature mostly influences their prescription. Physicians feel that there is minimal information on adverse drug reaction, comparison with other drugs, price, drug interactions and clinical trial results and contraindications. Likert score of 4.8, 4.7, 4.6, 4.6, 4.5 and 3.9 respectively. $41.07 \%$ physicians prefer pamphlets, and leave behind leaflet. Whereas they consider randomized controlled trials, meta-analysis and case controlled or cohort studies as significant references, with likert score 4.9, 4.7, and 4.6 respectively.

Conclusion: There is need for strong regulatory infrastructure and monitoring of the content of pharmaceutical promotional activities. Therefore, in the absence of effective regulations and standards physicians should be aware of the risks of using non independent information sources.
\end{abstract}

Keywords: Pharmaceutical promotion, Promotional literature, Information sources, Prescribing influences

\section{INTRODUCTION}

In this era of aggressive marketing of pharmaceutical products, promotional literatures play a critical role. W.H.O. (World Health Organization) defines Drug Promotion as "All the information and persuasive activities of manufacturers and distributors, the effect of which is to induce prescription, supply, and purchase and/or use of medicinal drugs."1

Promotional material of the manufacturers includes pamphlets, brochures, flipcharts and CDs. These materials are routes to reach the physicians for Pharmaceutical representatives. Undoubtedly, the pharmaceutical promotional activities have powerful influences on prescribing behaviour of the clinicians although this influence may be more subliminal rather than overt. ${ }^{2}$
Drug promotion and marketing make up a very large part of the activities of pharmaceutical companies in India. For the drug promotion, in addition to other activities, companies usually use the written material supposedly showing all the good and bad aspects about the concerned drug. These advertisements can be highly informative as long as they are critically appraised. ${ }^{3}$ However, if these are accepted without any question, can contribute to irrational prescribing. Ideally, drug promotional literature should provide health care professionals with substantial information. However, the information contained in promotional material may be inadequate ${ }^{4}$ or altogether inaccurate. ${ }^{5}$

So we propose to undertake this study to assess physicians' perspective regarding pharmaceutical promotional material. We sought for physician opinion regarding drug promotional literature and make an 
objective assessment about their opinion on current drug promotional methods.

\section{Objective}

To know the physician opinion regarding drug promotional literature, influence of promotional literature on their prescription patterns, type of promotional material preferred and the significance of the references cited in support of the claims and make an objective assessment about their opinion on current drug promotional methods at a tertiary care hospital.

\section{METHODS}

All resident doctors, house officers, medical officers and faculty members of the departments from clinical subjects were part of the study. However, some specialties such as radiology, pathology, pre and paraclinical specialties were excluded because doctors in these specialties typically prescribe few medications to patients and would therefore potentially be targeted less by medical representatives. The study protocol was reviewed and approved by the Institutional Ethics committee. Doctors were invited to voluntarily participate in the anonymous survey. Each survey questionnaire form was accompanied by an Informed consent form and a volunteer information sheet. The survey was conducted between August and October 2012.Demographic data such as age, years of practice, cadre/designation and department of prescribing physicians was noted. The questions were based on 4 Major issues pertaining to promotional literature.

1. Physicians' opinion about influence of content in drug promotional literature on their prescription.

2. Information which the physicians think is missing in the promotional literature. For this a 14 -item were assessed using a Likert scale with a range of 1 to 5 was used, $5=$ finds the information minimum number of times and $1=$ means you find the information most of the times.

3. Source/Type of promotional material preferred by the physicians.

4. Significance as per the physician's point of view of evidences presented as references in the promotional literature. A 6- item assessment measured physicians view on the significance of the references. Once again a 5-category Likert scale was used, ranging from $5=$ Most Significant and $1=$ least significant.

The objectives of the study were also personally explained to all participants as well as explanations regarding the techniques employed to assure confidentiality and anonymity. If agreeable to participation, the doctors were provided with the questionnaire to complete at a convenient time. If a doctor was not able to fill out the questionnaires because of a heavy workload or were not available, they were visited a second and third time to encourage participation. All the collected sealed questionnaires were not opened until the entire data collection period was completed. The data from the survey was entered into Microsoft Excel 2007. The results were presented as percentages and absolute number.

\section{RESULTS}

A total of 221 questionnaires (250 of those originally sent) were returned. Out of these 14 were incomplete and were not used for final analysis. Thus total 207 questionnaires were analysed. The respondents comprised of $28 \%$ faculty and $72 \%$ residents. The results throughout are given in percentages. Table 1 summarizes the demographic characters of the respondents. Maximum respondents were from Medicine and Surgery departments i.e. $18.36 \%$ $(n=38)$ and $11.60 \%(n=24)$ respectively.

Table 1: Demographic characters.

\begin{tabular}{|c|c|}
\hline Mean Age (years) & $36.4 \pm 14($ mean \pm SD $)$ \\
\hline $\begin{array}{l}\text { Mean years of Practice } \\
\text { (years) }\end{array}$ & $13.4 \pm 9($ mean $\pm \mathrm{SD})$ \\
\hline \multicolumn{2}{|l|}{ Cadre $(\%)$} \\
\hline House officers & $14.7(n=24)$ \\
\hline Medical officers & $13.5(\mathrm{n}=22)$ \\
\hline Residents & $27.6(n=45)$ \\
\hline Faculty & $29.4(n=48)$ \\
\hline \multicolumn{2}{|l|}{ Area of specialization (\%) } \\
\hline General medicine & $18.36(\mathrm{n}=38)$ \\
\hline General surgery & $11.6(n=24)$ \\
\hline Obstetrics and Gynaecology & $9.66(n=20)$ \\
\hline Paediatrics & $6.76(n=14)$ \\
\hline Ophthalmology & $3.86(n=8)$ \\
\hline E.N.T & $2.9(n=6)$ \\
\hline Orthopaedics & $6.76(n=14)$ \\
\hline Psychiatry & $6.28(n=13)$ \\
\hline Respiratory Medicine & $3.86(\mathrm{n}=8)$ \\
\hline Skin and Venereal diseases & $5.80(n=12)$ \\
\hline $\begin{array}{l}\text { Medicine Super specailties } \\
\text { (Endocrinology, } \\
\text { Nephrology, Neurology, } \\
\text { Urology, Cardiology) }\end{array}$ & $12.56(n=26)$ \\
\hline $\begin{array}{l}\text { Surgical super specialities } \\
\text { (C.V.T.S, Plastic surgery, } \\
\text { Neurosurgery) }\end{array}$ & $11.60(n=24)$ \\
\hline
\end{tabular}

Figure 1 indicates that $59.5 \%(n=123)$ physicians are of the opinion that the content in a promotional literature mostly influences their prescription, $22.3 \%(n=46)$ feel 


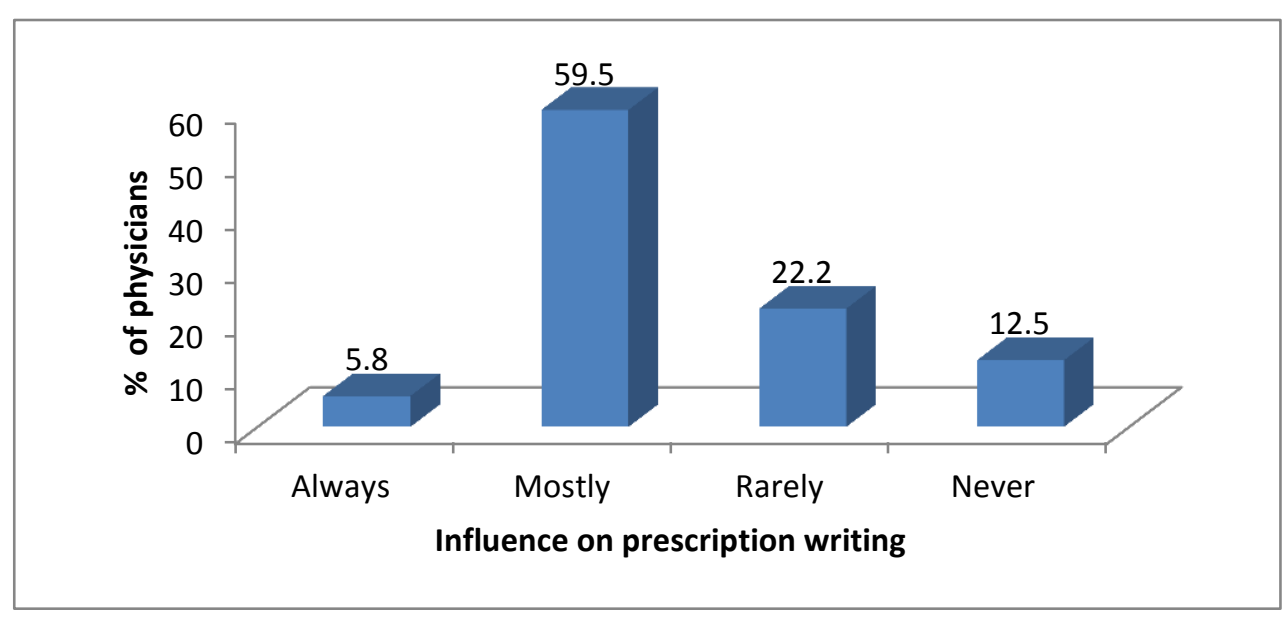

Figure 1: Physicians' opinion about influence of content in a promotional literature on their prescriptions.

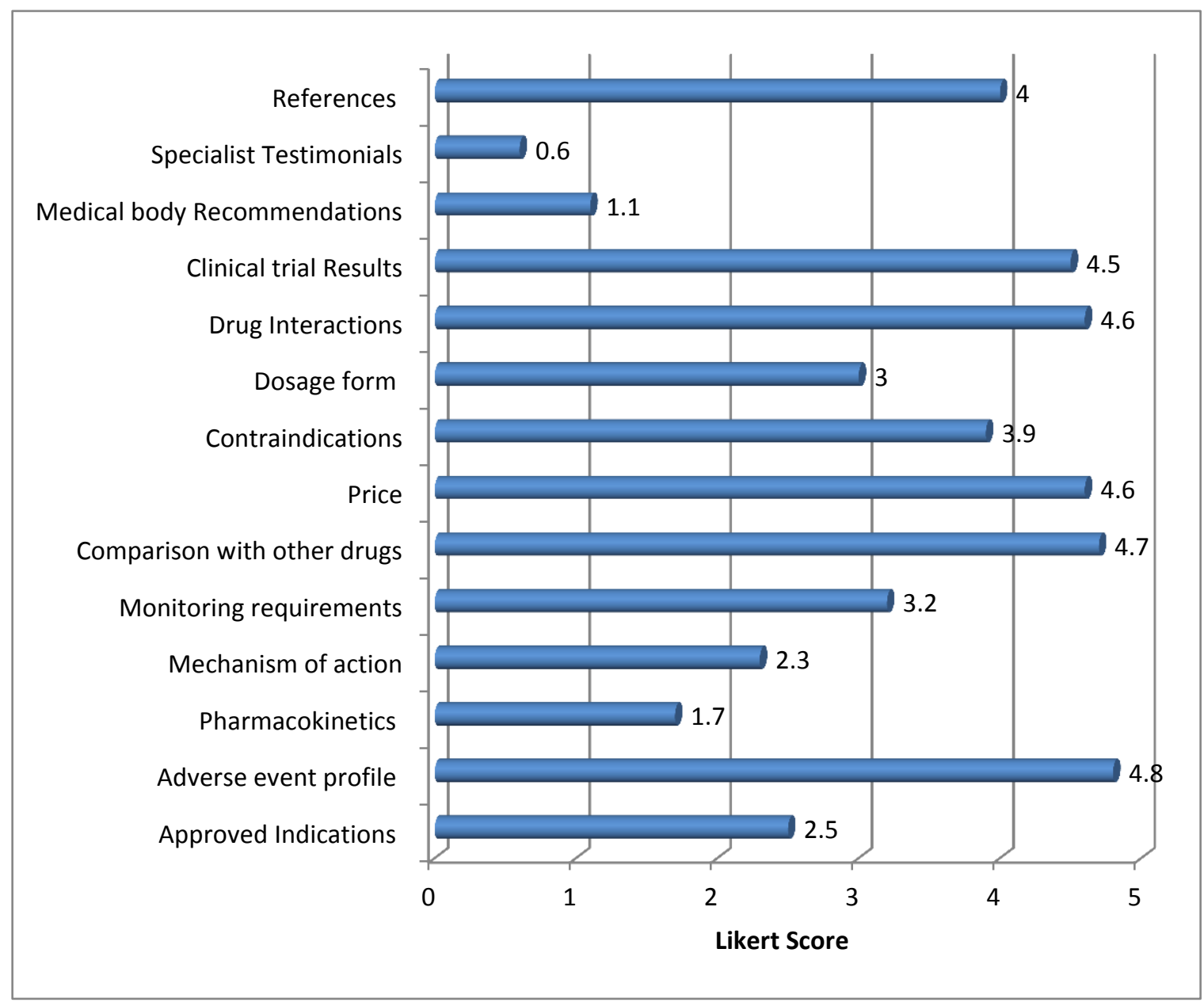

Figure 2: Information a physicians think is missing in a promotional literature.

$\mathrm{X}$ axis: physicians' perceived Likert score for various type of information in a promotional literature.

Likert score derived from 5 point scale were $5=$ finds the information minimum number of times and $1=$ finds the information most of the times. 


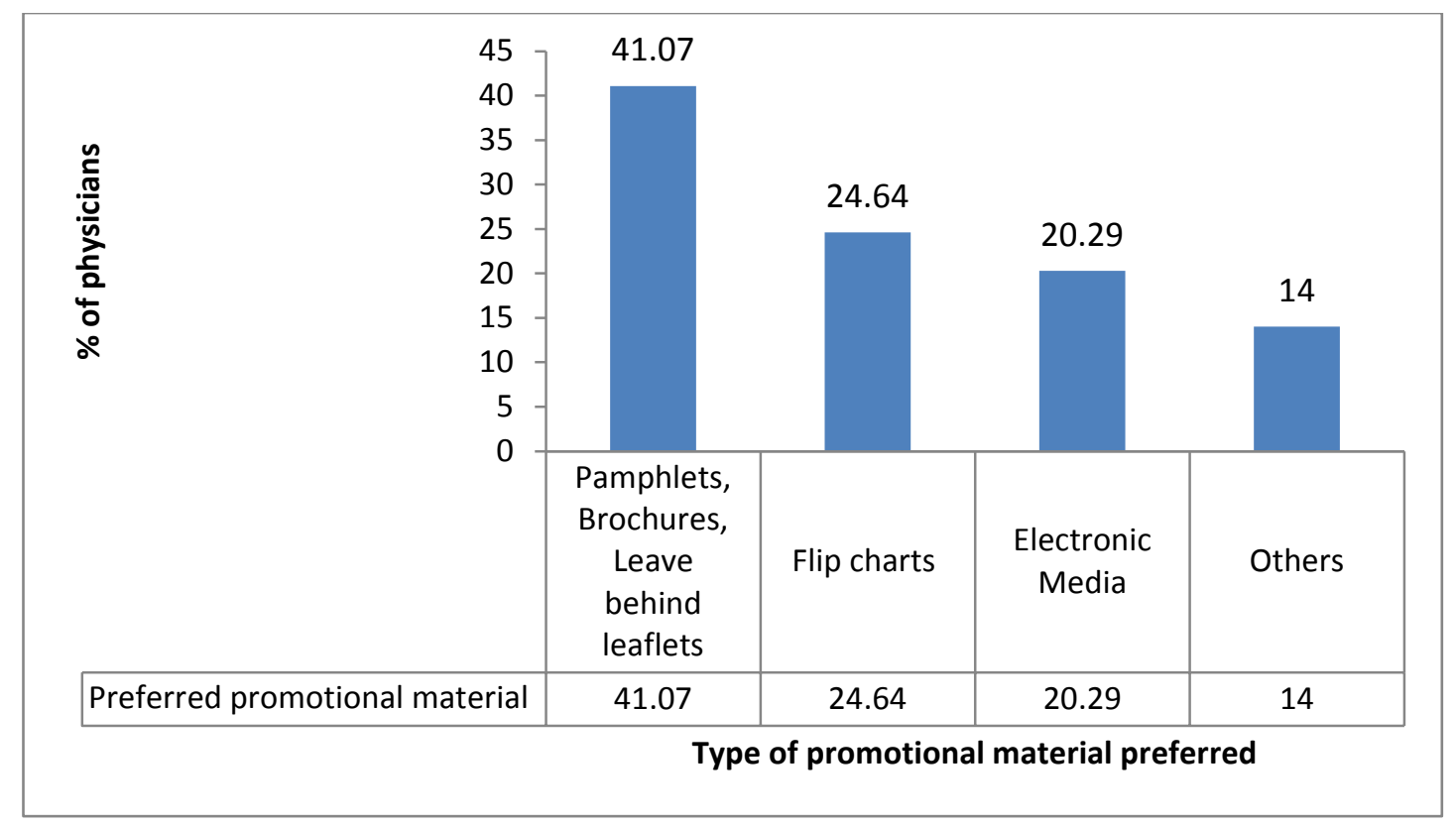

Figure 3: Type of material preferred by physicians as source of information.

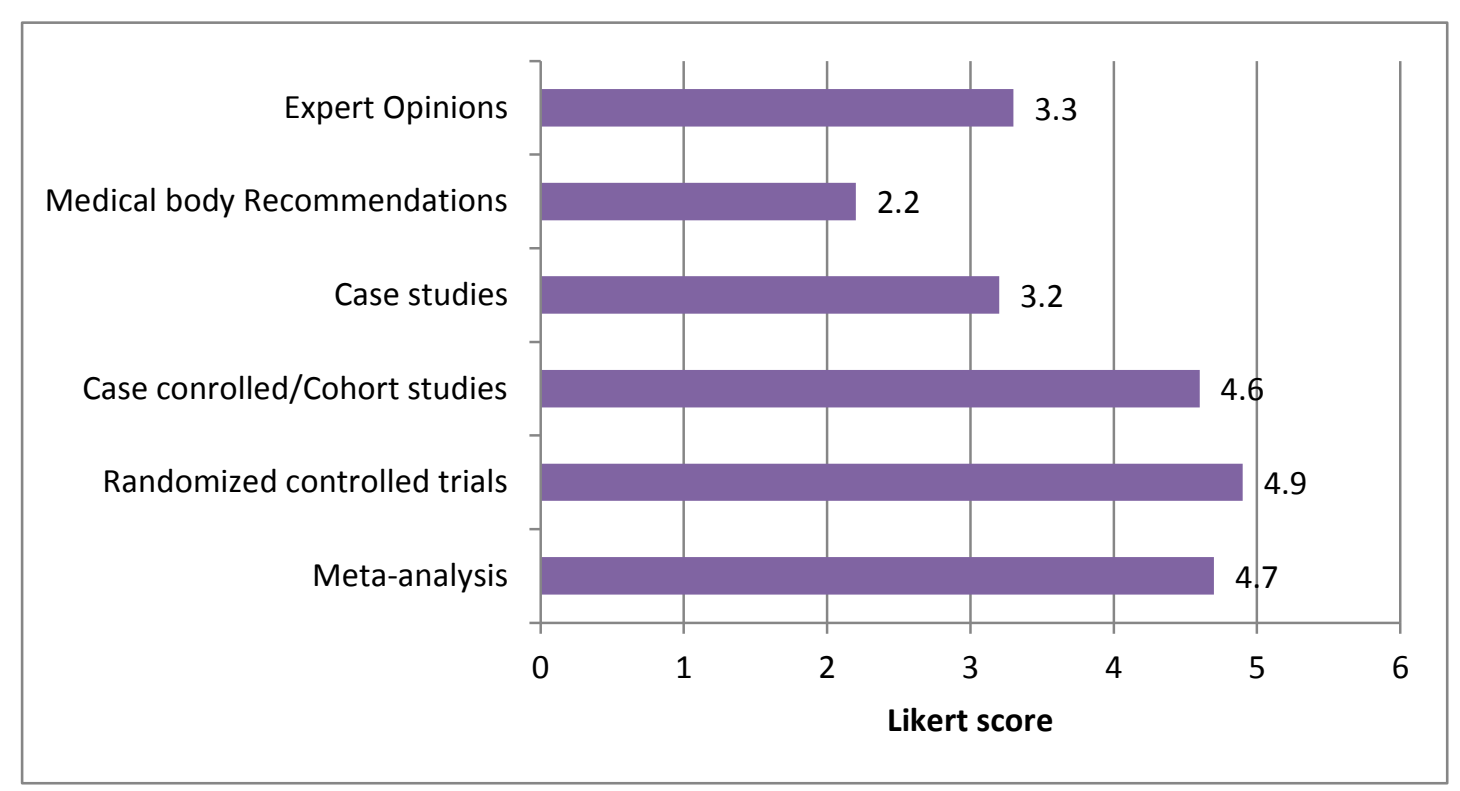

Figure 4: Significance of evidences presented as references in the promotional literature.

$\mathrm{X}$ axis: physicians' perceived Likert score for significance of various type of references.

Likert score derived from 5 point scale were $5=$ most significant and $1=$ least significant.

that there is rarely any influence, $13 \%(n=26)$ feel that the content in promotional literatures never influenced their prescriptions while $5.2 \%(\mathrm{n}=12)$ feel that the content in a promotional literature always influences their prescription. Figure 2 shows that Adverse drug reactions (Likert score: 4.8) i.e. safety profiles are the most common types of information which the physicians look for and find missing. The second rank was for information on comparison with other drugs (Likert score: 4.7) used for the same condition which was followed by minimum presence of information about by price, drug interactions, clinical trial results and contraindications, likert score 4.6, 4.6, 4.5, 3.9 respectively. Figure 3 shows the reactions of all physicians regarding the type of material preferred for drug information clearly shows that $41.07 \% \quad(n=85)$ physicians prefer pamphlets brochures and LBL (leave behind leaflets) from medical representatives. $24.64 \%$ $(n=51)$ prefer electronic media (e.g. audiovisual aids, emails, CD/ DVDs etc) followed by preference for flip 
chart i.e. $20.29 \%(n=42)$. Whereas $14 \%(n=29)$ preferred other sources like small gifts or mementos mentioning the product name. Figure 4 shows Likert score for physicians' opinion about significance or references. Randomized clinical trial were considered most significant (4.9), followed by meta-analysis (4.7), case controlled or cohort studies (4.6), expert opinions (3.3), case studies (3.2) while medical body recommendations (2.2) were considered least significant.

\section{DISCUSSION}

The W.H.O. has laid down a set of ethical criteria for medicinal drug promotion, suggesting minimum essential information required in a promotional literature. It is important, however, that the information provided in a promotional literature is accurate, complete and balanced. Usually pharmaceutical companies make an attempt to highlight and present only the positive aspects and advantages of their products, but downplay any negative information. 6,7

However, by not presenting this information the credibility of the information provided is diminished and may also question the truthfulness and accuracy of their presentations and content. The consequence of omitting some risk-related information can also have potentially tragic consequences for patients. Under the FD\&C Act and FDA's implementing regulations, promotional pieces (such as promotional labelling for drugs and devices and advertisements for prescription drugs and restricted devices) making claims about a product are deemed misleading if they fail to disclose certain information about the product's risks. ${ }^{8}$ In our study we sought for investigated for the physicians opinion and their expectations from promotional literatures.

Most of the practitioners rely on promotional literature for new information and also may believe that all significant risk-related information has been presented, especially if some risks are highlighted. It may result in doctors failing to inform their patients of important considerations, and, at worst, doctors may make inappropriate prescription decisions. Ethical issues arise if content in a promotional literature attempt to deceive medical practitioners by omitting risk-related information or by using a language that is confusing and by making false claims. Misleading and inaccurate drug-related information is likely to be worse in countries where independent sources of drug information are absent or restricted.

The primary goal of pharmaceutical advertisements is to convince clinicians to prescribe their product. Doctors themselves report that they often use promotion as a source of information about new drugs. The primary source of information about the drugs for the General practitioners was found to be the promotional literatures by pharmaceutical representatives. ${ }^{9,10}$ In our study, doctors themselves have the opinion that the information in promotional literature influences their prescriptions most of the times. Promotion influences attitudes more than doctors realize. Research clearly shows that doctors who report that rely more on promotional literature and prescribe more often and adopt information from such promotions more quickly. ${ }^{11,12}$ Also, studies which look at the impact of promotion on overall sales usually show increased sales after promotional activities. ${ }^{13}$ They were often not given critical details such as a drug's adverse reactions. Companies ensured that the information given to doctors was limited and biased towards their drugs, and that such promotional material was not left with the doctor. $^{14}$

In our study ADRs and comparison with other drugs are the most sought after information and found missing. Also we found that many physicians seek for information about price, contraindications and clinical trial results which is missing most of the times. This imparts incomplete knowledge about the drug and might lead to irrational prescription. Hence if companies provide complete information about the product, irrational prescription practices shall diminish. So we recommend that companies should take an initiative to curb such practices by providing information that is most sought after by physicians. Also there is need for binding regulations in order to ensure that these guidelines are being implemented. Our findings also suggest that physicians prefer pamphlets, brochures and LBL (leave behind leaflets) as the source for information which was followed by preference for flip charts. These sources may be primarily targeted by the companies for a good impact.

This result is in concordance with a number of previous studies, which reported that pharmaceutical promotional materials and representatives provide low-quality information. A study performed in Sudan found that approximately one-third of 160 pharmaceutical representatives interviewed admitted they did not always mention contraindications, precautions or drug interactions, and only $4.3 \%$ mentioned the side effects of their promoted products during drug-detailing visits. ${ }^{15}$

The Ethical Criteria for Medicinal Drug Promotion developed by the World Health Organization (WHO) suggest the types of information that, as a minimum, should be contained in a journal advertisement (WHO, 1988). ${ }^{1}$ The aim is to ensure that basic information needed for prescribing decisions is present. Studies show that printed advertisements do not meet regulations and guidelines in force in various countries. ${ }^{16}$ Neither self-regulatory systems nor review by journal editors provide effective control on drug advertising. More recent work analysing advertisements in India, Brazil and the Russian Federation shows that they continue to leave out essential information recommended by W.H.O. ${ }^{17}$

Just because each of the categories of information is present in an advertisement does not necessarily mean 
that the advertisement will give a complete picture of the medicine's safety and effectiveness and how to prescribe. Studies of promotion by drug company representatives suggest that the guidelines and regulations that should control them are ineffective. While representatives usually mentioned the indications for their drugs, they did not bring up prices, side effects, or contraindications.

The content often cite external documents in support of their claims, but studies have shown that these claims may be misleading, distort the reporting of scientific data or fail to provide enough information to accurately interpret the data they present. The transparency of pharmaceutical ads is important for 2 reasons. First, there is evidence that physician prescribing is influenced by pharmaceutical advertisements, Second, the pharmaceutical industry views advertisements as one way in which they can educate physicians." 90 Given the potential for misrepresentation, health care professionals should be able to examine the cited references to determine whether the manufacturer's claims are justified. ${ }^{18}$ Most of these claims are not supported by enough data to be used in decision making process and even if citations provided these are from unpublished data or not peer reviewed references. ${ }^{19,20,21,22}$ Only a few claims are entirely evidence based with higher level of evidence. $^{23,24}$ Our findings suggest that the physicians prefer randomized controlled studies and meta-analysis the most, which are studies with higher level of evidence and thus pharmaceutical companies, should make an attempt to cite references which have higher strength of evidence and are retrievable or easily accessible.

Reference citation is usually given to earn credibility, but it is very common for pharmaceutical ads cited a large number of unpublished documents/ data of file. Supporting scientific evidences is an important aspect to be considered in evaluating promotional literature. Systematic reviews of randomized controlled trials are the strongest level of evidence (i.e., Level I evidence). Other levels of evidence in descending order of strength include non-randomized trials, cohort studies, casecontrol studies, descriptive or qualitative studies and reports of expert committees. ${ }^{18}$ Scientific information should not be presented in a form that might bias the judgment of the physician. In general, the references could be evaluated using the above mentioned points. Ultimately it is the physicians' experience who decides the quality and credibility of references cited. In our study, the physicians' we consider that the physicians are aware of the strength of evidences as most randomized controlled trials were considered as the most significant references. Pharmaceutical companies should make an effort to quote standard references with higher strength of evidence and which can be easily accessible for physicians. In our study we didn't intend to assess the accuracy of the content in a promotional literature but our prime objective was to know the prescribers opinions regarding their perceptions of the information provided. Further studies that directly access the quality of the information provided during visits can be performed. The survey revealed that doctors largely believe that the provision of drug information in promotional literatures is sometimes incomplete and biased. Incomplete presentation of risk related information, and ignorance of equivalent or alternative products was common. One assumption underlying the project was that health care practitioners actually do perceive a distinct need for improvement in the quality of their information in certain professional subject areas.

The use of various types of information sources as affected by Pharmaceutical companies should ensure that the content they publish is in accordance with the guidelines. However, in developing countries like India there is no strong regulatory infrastructure, and there is no monitoring of the content of pharmaceutical promotional activities. Therefore, in the absence of effective regulations and standards for provision of pharmaceutical promotional information, physicians should be aware of the risks of using nonindependent information sources.

Funding: None

Conflict of interest: None declared

Ethical approval: Approved by the Institutional Ethics Committee

\section{REFERENCES}

1. Criteria for Medicinal Drug Promotion, World Health Organisation. Endorsed by the 33rd World Health Assembly, May 1986, Resolution No. WHA21.41. Available: http://apps.who.int/medicinedocs/en/d/Js16520e/6.ht ml. Accessed 1 January 2013.

2. Avorn J, Chen M, Hartley R. Scientific versus commercial sources of influence on the prescribing behaviour of physicians. American Journal of Med 1982;731:4-8.

3. Levy $\mathrm{R}$. The role and value of pharmaceutical marketing. Arch. Fam. Med 1994; 3:327-32.

4. Gutknecht D.R. Evidence-based advertising? A survey of four major journals. J Am Board Fam Pract 2001;14:197-200.

5. Villanueva P, Peiró S, Librero J and Pereiró I. Accuracy of pharmaceutical advertisements in medical journals. Lancet 2003;361:27-32.

6. K Alam, AK Shah, P Ojha, S Palaian, PR Shanka. Evaluation of drug promotional materials in a hospital setting in Nepal. South Med Review. 2009;2:2-6.

7. Islam MS, Farah SS. Misleading promotion of drugs in Bangladesh: evidence from drug promotional brochures distributed to general practitioners by the pharmaceutical companies. J Public Health. 2007;29:212-3.

8. Guidance for Industry Presenting Risk Information in Prescription Drug and Medical Device Promotion: ucm 155480. 
9. DK Rohraa, AH Gilania, IK Memona, G Pervenb, MT Khan, H Zafarb, et al. Critical evaluation of the claims made by pharmaceutical companies in drug promotional material in Pakistan. J Pharm Pharmaceut Sci 2006;9:50-59.

10. CS Lundsborg, LO Hensjo, LL Gustafscan. Drug information sources: reported preferences by general practitioners. Drug Information Journal 1998;32:777-85.

11. Layton MR, Sritanyarat W, Chadbunchachai S, Wertheimer AI. Sources of information for new drugs among physicians in Thailand. Pharm World Sci. 2007;29:619-27.

12. Furtado C, Periera JA. Information sources and prescribing in the Lisbon region. Acta Med Port. 2006;19:301-8.

13. P. Norris, A Herxheimer, J. Lexchin, P. Mansfield. Drug promotion: What we know, what we have to learn. World Health Organization and Health Action International

2005.www.who.int/medicines/areas/rational_use/dru gPromodhai.pdf.

14. Drug promotional practices in Mumbai: a qualitative study. N Roy, N Madhiwalla, S Pai. Indian Journal of Medical Ethics 2007;4:57-61.

15. Idris KM, Mustafa AF, Yousif MA. Pharmaceutical representatives' beliefs and practices about their professional practice: a study in Sudan. East Mediterr Health J. 2012;18:821-6.

16. Ziegler MG, Lew P, Singer BC. The accuracy of drug information from pharmaceutical sales representatives. Journal of American Medical Association.1995;273:1296.

17. Joel Lexchin. Analysing Pharmaceutical Advertisements in Medical Journals. Herxheimer 1993. http://www.politicsofmedicines.org/articles/analysin g-pharmaceutical-advertisements-in-medicaljournals.

18. Cooper RJ, Schringer DL. The availability of references and the sponsorship of original research cited in pharmaceutical advertisements. Canadian Med Assoc J. 2005;172:487-91.

19. Bhattacharyya T, Tornetta P, Healy WL, Einhorn TA. The validity of claims made in orthopaedic print advertisements. J Bone Joint Surg Am. 2003; 85:1224-8.

20. Mindell J, Kemp T. Evidence based advertising? Only two fifths of advertisements cited published, peer reviewed references. BMJ. 1997;315:1622.

21. Del Signore A, Murr AH, Lustig LR, Platt MP, Jalisi S, Pratt LW, et al. Claim validity of print advertisements found in otolaryngology journals. Arch Otolaryngol Head Neck Surg. 2011;137:74650.

22. Greving JP, Denig $\mathrm{P}$, de Zeeuw D, HaaijerRuskamp FM. Claims in advertisements for antihypertensive drugs in a Dutch medical journal. J Hypertens. 2007; 25:713-22.

23. VV Shetty, AV Karve. Promotional literature: How do we critically appraise? Journal of Postgraduate Medicine 2008; 54:217-21.

24. Winkelen P, Denderen JS, Vossen CY, Huizinga TW, Dekker FW. How evidence-based are advertisements in journals regarding the subspecialty of rheumatology? Rheumatology 2006;45:1154-7.

doi:10.5455/2319-2003.ijbcp20131006

Cite this article as: Chitnis K, Limaye A, Bhosale M. Pharmaceutical promotional literature: opinions of physicians in a tertiary care hospital in Mumbai. Int $\mathbf{J}$ Basic Clin Pharmacol 2013;2:541-7. 